\title{
Quantitative Analysis of Cell Types during Growth and Morphogenesis in Hydra
}

\author{
H. Bode*, S. Berking, C. N. David, A. Gierer, H. Schaller, and E. Trenkner \\ Max-Planck-Institut für Virusforschung, Molekularbiologische Abteilung, \\ 7400 Tübingen, Spemannstraße 35, Germany
}

Received June 22, 1972

\begin{abstract}
Summary. Tissue maceration was used to determine the absolute number and the distribution of cell types in Hydra. It was shown that the total number of cells per animal as well as the distribution of cells vary depending on temperature, feeding conditions, and state of growth. During head and foot regeneration and during budding the first detectable change in the cell distribution is an increase in the number of nerve cells at the site of morphogenesis. These results and the finding that nerve cells are most concentrated in the head region, diminishing in density down the body column, are discussed in relation to tissue polarity.
\end{abstract}

\section{Introduction}

To study processes of morphogenesis and differentiation in higher organisms at the cellular or molecular level, a simple organism like hydra provides several advantages. Among these are its high capacity of regeneration, a relatively simple morphology, and the occurrence of only a few cell types.

Many studies have been carried out examining regeneration, polarity of regeneration, budding, and cell differentiation in hydra (reviewed by Kanaev, 1952; Tardent, 1963; Burnett, 1966; Webster, 1971). These processes have been studied at the tissue level of organization, or if at the cellular level, then only qualitatively. For a better understanding of these phenomena it will be necessary to have quantitative knowledge of the changes occurring in the distribution of cell types. For example, the initial shift in cell type distribution in the budding zone and the subsequent appearance of cell types in the developing bud may help to frame the critical questions about the process of budding. Similarly, quantitative changes in cell distribution of regenerating animals will help to evaluate the importance of cell migration and differentiation in this process and may give some indication of passible sources and targets of morphogenetic gradients which control hydra morphology.

Hydra tissue consists of 7 basic cell types: epithelio-muscular, digestive, interstitial, gland, mucous, nematocytes, and nerves. The first 5 are dividing cell types while the last 2 are the non-dividing differentiation products presumably of the interstitial cell (Lentz, 1966). An understanding of the regulation of interstitial cell (I-cell) differentiation into nematocytes and nerves as well as its own (stem cell) proliferation requires knowledge of the pool sizes of cell types in the differentiation pathway and the transition of cells through these pools. Be-

* Present Address : Developmental Biology, University of California at Irvine, Irvine, California 92664. 
cause of their possible role in morphogenesis and tissue polarity, the changes in the distribution of nerve cells during budding and regeneration are of special interest.

To obtain such data three methods are available. Tardent (1954) used a whole mount technique to examine the distribution of interstitial cells throughout the epithelial layer of hydra. Burnett (1966) and Campbell (1967) used serial sections to count epithelial, gland, interstitial, mucous, and nematoblast cells in $H$. littoralis. In the present paper we use a maceration technique (David, 1972), which allows a quantitative examination of all the basic cell types-including nerve cells.

We have used this maceration technique to examine the distribution of cell types in all regions of $H$. altenuata. Further, we examined the changes that occur in the cell distribution of (1) a developing bud, (2) a regenerating surface, (3) starving animals, (4) animals grown at various temperatures. The results show that temperature and feeding conditions mainly influence the rate of growth and the size of the animal (number of cells/individual), but to a much lesser extent the overall cell distribution. During budding and regeneration (foot and head) the first visible change in the cell distribution is an increase in the density (or cell number) of nerve cells suggesting their possible role in morphogenesis.

\section{Materials and Methods}

Hydra attenuate were used for all experiments. The hydra were obtained from P. Tardent, Zürich, in 1966, and have been cultured asexually in our laboratory since then. The hydra were mass cultured according to Loomis and Lenhoff $(1956)$ in a medium containing $10^{-3} \mathrm{M}$ $\mathrm{CaCl}_{2}, 1.25 \times 10^{-5} \mathrm{M}$ EDTA in tap water. The animals were fed daily with Artemia nauplii (1-2 Artemia per hydra) and washed about 4 hours later. The culture was maintained at about $18^{\circ} \mathrm{C}$.

The animals used in all experiments were starved for at least 1 day. The various regions in standard animals (see Results) were defined according to Wolpert et al. (1971): the hypostomal region (including hypostome and tentacles) is cut just proximal to the base of the tentacles, the tentacles are removed afterwards; the gastric region (regions 1-4) extends from the hypostome cut to a cut just distal to the most immature bud; the budding region extends from the gastric region cut to a cut proximal to the most mature bud; the remainder of hydra is peduncle and basal disk whereby the peduncle is about $3 / 4$ of the length and the basal disk about $1 / 4$. Budding stages and regenerating pieces are defined diagramatically in the text.

The maceration technique for obtaining single cell suspensions from hydra tissue and the identification of cell types have been described in the preceding paper (David, 1972). The absolute number of cells in pieces or whole animals was obtained by macerating a known number of identical pieces or animals in a known volume of maceration solution and determining the cell concentration with a Schilling Kreuznetz cell counter $(0.1 \mathrm{~mm}$ depth).

Mature nematocytes, although recognizable in maceration preparations, are difficult to count in battery cells. Since the mature organs are extremely stable to shearing they can be counted most accurately in homogenized preparations. Pieces of tissue were sheared by repeatedly forcing them through a number 16 needle attached to a syringe. Data on nematocytes in tentacles were obtained with this method.

\section{Presentation of the Data-Statistical Analysis}

The data in the tables are expressed as the total number of cells per piece (animal) and as the percentage of a given cell type in a macerate of that piece. The number of cells of a specific type was calculated from these two values. The data presented are the average of several 
experiments. The accuracy of the numerical data is limited by errors in counting, errors in cell classification, and biological variability among animals. In the following we have analyzed these effects.

(1) Counting errors: Since macerates contain clusters of cslls (e.g. nests of I-cells) the distribution of cells in a counting chamber or on slides is not random. Therefore the counting error should be greater than predicted by the Poisson distribution. We have determined the counting error in our measurements as follows. For any given sample the mean cell number $(\bar{x})$ was determined from 4 independent cell counts (each approximately 300 cells) of the same area in a cell counting chamber. From 10 such experiments we have calculated the mean of the standard errors of the mean to be $\bar{s}_{\bar{x}}=5.76 \%$ (expressed as \% of $\bar{x}$ ).

(2) Biological variability in cell number per hydra: 10 hydra developing their first bud were macerated individually and the cell number per hydra determined (Hypostome and tentacles were excised before maceration). The mean cell number per hydra was found to be $59071 \pm 14230$ (standard deviation). Because of this variation in size among individual animals, samples containing 10 or more animals were macerated together in all experiments reported in this paper. For 5 such preparations of 10 hydra the mean cell number per hydra was found to be $54506 \pm 5004$ (standard deviation).

(3) Cell classification errors: Classification of most of the cells in a maceration preparation is not difficult although the classification of a few cells is ambiguous (e.g. cells which differentiate from one type to another and are in between). Fortunately such cells are rare. In one preparation of cells counted by 5 investigators ( 1000 cells/investigator) the standard deviation of the individual cell counts was: $2-3 \%$ for epithelial cells, I-cells and nematoblasts, and $0.5-1.0 \%$ for nerve cells and gland cells. These standard deviations are about the same as those expected from the statistics of counting alone and hence the contribution of classification errors to the final standard deviation is small. However, to minimize further the effect of such classification errors, the same investigators have counted all samples in each experiment. The data presented are the average of these individual results.

(4) Biological variability in cell distribution: Table 1 gives the mean percentage $(\bar{x})$ and the standard deviation $(s)$ for each cell type averaged over 10 hydra analyzed individually and in 5 samples containing 10 hydra macerated together. In all experiments 1000-1500 cells were counted. The variability of the percentage of a given cell type among individual animals

Table 1. Cell distribution-Statistical accuracy of the method

\begin{tabular}{lcccrrrrr}
\hline & & & $\begin{array}{l}\text { Epithelio- } \\
\text { muscular } \\
\text { digestive }\end{array}$ & $\begin{array}{l}\text { Big } \\
\text { inter- } \\
\text { stitial }\end{array}$ & $\begin{array}{l}\text { Little } \\
\text { inter- } \\
\text { stitial }\end{array}$ & $\begin{array}{l}\text { Nemato- Nerve } \\
\text { blast }\end{array}$ & Gland \\
\hline Single animals & $\bar{x}$ & $\%$ & 28.35 & 18.38 & 18.62 & 27.54 & 2.74 & 4.40 \\
& $s$ & $\%$ & 4.37 & 2.63 & 3.96 & 3.86 & 0.61 & 0.95 \\
\hline $\begin{array}{l}\text { Preparations } \\
\text { of 10 hydra }\end{array}$ & $\bar{x}$ & $\%$ & 24.83 & 18.64 & 19.61 & 29.16 & 2.95 & 4.81 \\
& $s$ & $\%$ & 1.47 & 2.69 & 1.95 & 2.40 & 0.48 & 0.89 \\
& $\bar{x}$ & $\#$ & 13550 & 10186 & 10709 & 15839 & 1590 & 2648 \\
& $s \bar{x}$ & $\#$ & 726 & 868 & 746 & 514 & 63 & 306 \\
\hline
\end{tabular}

Hydra just developing their first bud were selected. Hypostomes and tentacles were removed before maceration since counting nematocytes in battery cells is difficult in maceration preparations. 10 animals were macerated individually and the cell distribution determined by several investigators. (At least 1000 cells were counted per hydra). The results of all 10 animals were averaged $(\bar{x})$ and the standard deviation $(s)$ calculated.

Preparations containing 10 hydra each were macerated, the cell distribution determined as above and the total cell number per hydra determined. The results of 5 such 10-hydra preparations were averaged $(\bar{x})$ and the standard deviation $(s)$ calculated. The number of each cell type per hydra in each preparation was also calculated. The average $(\bar{x})$ of these values and the standard deviation of the mean $\left(s_{\bar{x}}\right)$ are presented in the Table. 
is small and is not much reduced by pooling 10 animals. Thus despite variations in total cell number among individual animals of $\pm 25 \%$ there are only very small variations in cell composition.

In each of the $\mathbf{5}$ samples of 10 animals the number of cells of each cell type was calculated from the total cell number per hydra and the percentage of each cell type. Table 1 gives the mean $(\bar{x})$ of these 5 calculated values for each cell type and the standard deviation of the mean $\left(s_{\bar{x}}\right)$.

All the data presented in Results were obtained in preparations in which $10-20$ hydra (pieces) were macerated together similar to the data in the last 4 lines of Table 1 . The data in Results, however, are based on 2-3 times more counted cells per sample so that the standard deviation is smaller than in the experiments given in Table 1. For clarity of presentation most of the data in Results have been rounded off to the nearest percentage or 100 cells (50 cells in the case of nerve and gland cells). Both procedures are within the standard deviation $(s)$ for each cell type.

Particular importance is given in the text to the distribution of nerve cells in different regions of hydra and to changes in nerve cell numbers during budding and regeneration. Although the differences mentioned are all considerably greater than the standard deviation in the nerve cell determinations, those differences have in all cases been further checked for significance with the $\chi^{2}$ test. The statistical significance of differences between such numbers is given in the text and Tables as the probabilitiy of error, $p$.

\section{Results}

\section{Definition of Standard Hydra}

Mass cultures of well-fed hydra contain a mixture of animals : parent animals having 2-3 buds each, small animals without buds (these are mostly buds which have fallen off a parent animal in the previous 1-4 days), and medium sized animals with 1 bud. The "standard" hydra was defined as a large animal having 2 buds, one completely developed and one at an early stage of development. Such hydra were used to obtain the data in Table 3 , and also those on developing buds (Table 4). For regeneration experiments animals without buds were used from a well-fed culture (recently dropped-off buds.)

Variations in the size of hydra are due not only to the differences between the young bud and the mature parent, but also to the temperature of the culture and the feeding conditions. Fig. 1 gives the number of cells per hydra (not in. cluding tentacles) as a function of temperature: for newly dropped buds (buds which dropped from parent during preceding 24 hours), for animals with a very young bud (with just visible bud tip), and for mature animals with several buds. Animals grown at $16^{\circ} \mathrm{C}$ are larger in size and in cell number than hydra grown at $20^{\circ} \mathrm{C}$. This is true for all three types of animals. Raising the temperature to $26^{\circ} \mathrm{C}$ has little additional effect.

Table 2 a shows the effect of starvation on cell number and cell distribution. During the first days of starvation the animals still increase in cell number (from approximately 45000 cells the first day to 80000 cells the third day). From the third or fourth day on the cell number drops sharply-in the experiment cited in Table 2 a-from 80000 cells the third day to 50000 cells the fourth day. Control animals which were fed daily meanwhile had increased to 150000 cells. Longer periods of starvation lead to further decreases in cell number until the animals seemed to consist of head and foot only. The smallest animals investigated after 9 days of starvation had only $3000-5000$ cells. 


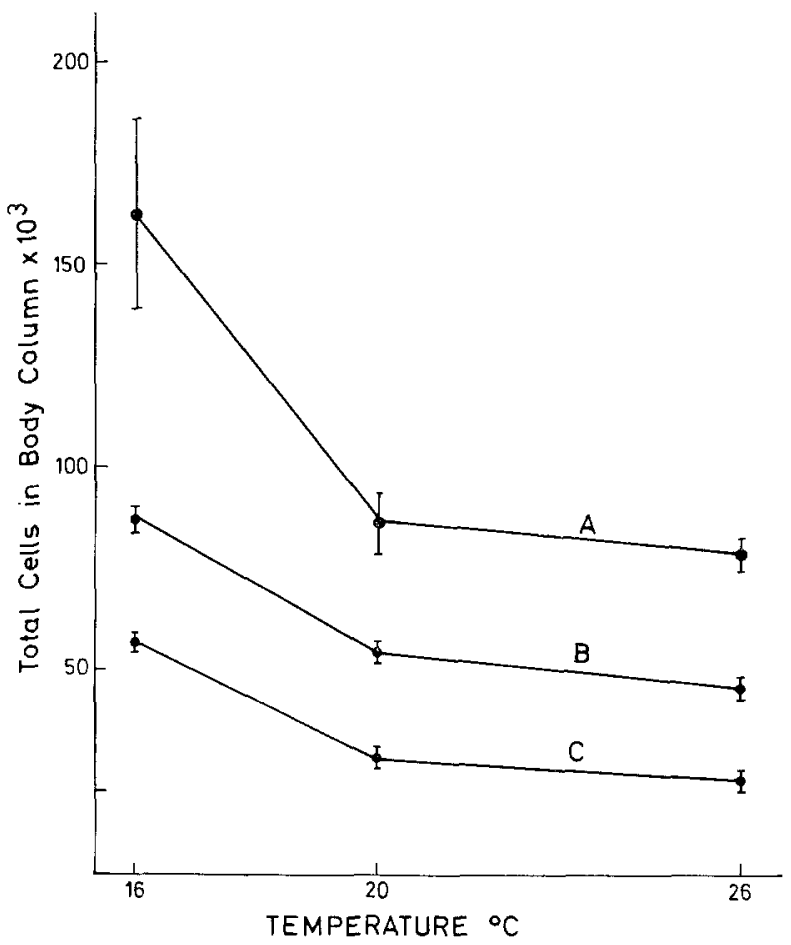

Fig. 1 A-C. Influence of temperature on cell number. Hydra were cultured with daily feeding at the indicated temperatures for 1-2 weeks before assaying. Tentacles and buds were removed from animals before macerating the body column and counting cells. 5-10 mature animals or $15-30$ buds or hydra with one bud were macerated together and the total cell number/animal determined. The values given are the mean and the standard error of the mean of 3-5 independent determinations. A mature hydra (individuals with $2-4$ buds); B hydra with one bud (freshly dropped buds were collected and cultured until the first bud started to appear); $\mathrm{C}$ buds dropped from mature animals during the previous 24 hours

Whereas the effect of temperature and feeding is very marked on the number of cells per animal, the changes in the cell composition are less extreme. As Table $2 \mathrm{~b}$ shows, heavy feeding (5-8 Artemia/day) versus normal feeding (1-2 Artemia/day) leads in the body column to an increase in epithelial cells relative to other cell types, especially nematoblasts. Starvation (Table 2a) on the other hand results in a relative increase in nerve and gland cells over epithelial cells and in a slight decrease in little I-cells and nematoblasts. Growth at $16^{\circ} \mathrm{C}$ causes a small increase in big and little I-cells relative to nematoblasts; growth at $26^{\circ} \mathrm{C}$ leads to an increase in nematoblasts and to a minor extent in nerve cells.

\section{Cell Distribution一Standard Hydra}

Table 3 gives the distribution of cell types and the total number of cells in each region for an average-sized standard hydra. These animals were grown at $18^{\circ} \mathrm{C}$ and had their buds removed just before analysis. Since epithelio-muscular cells (or battery cells in the tentacles) basically make up the outer tissue layer of the 


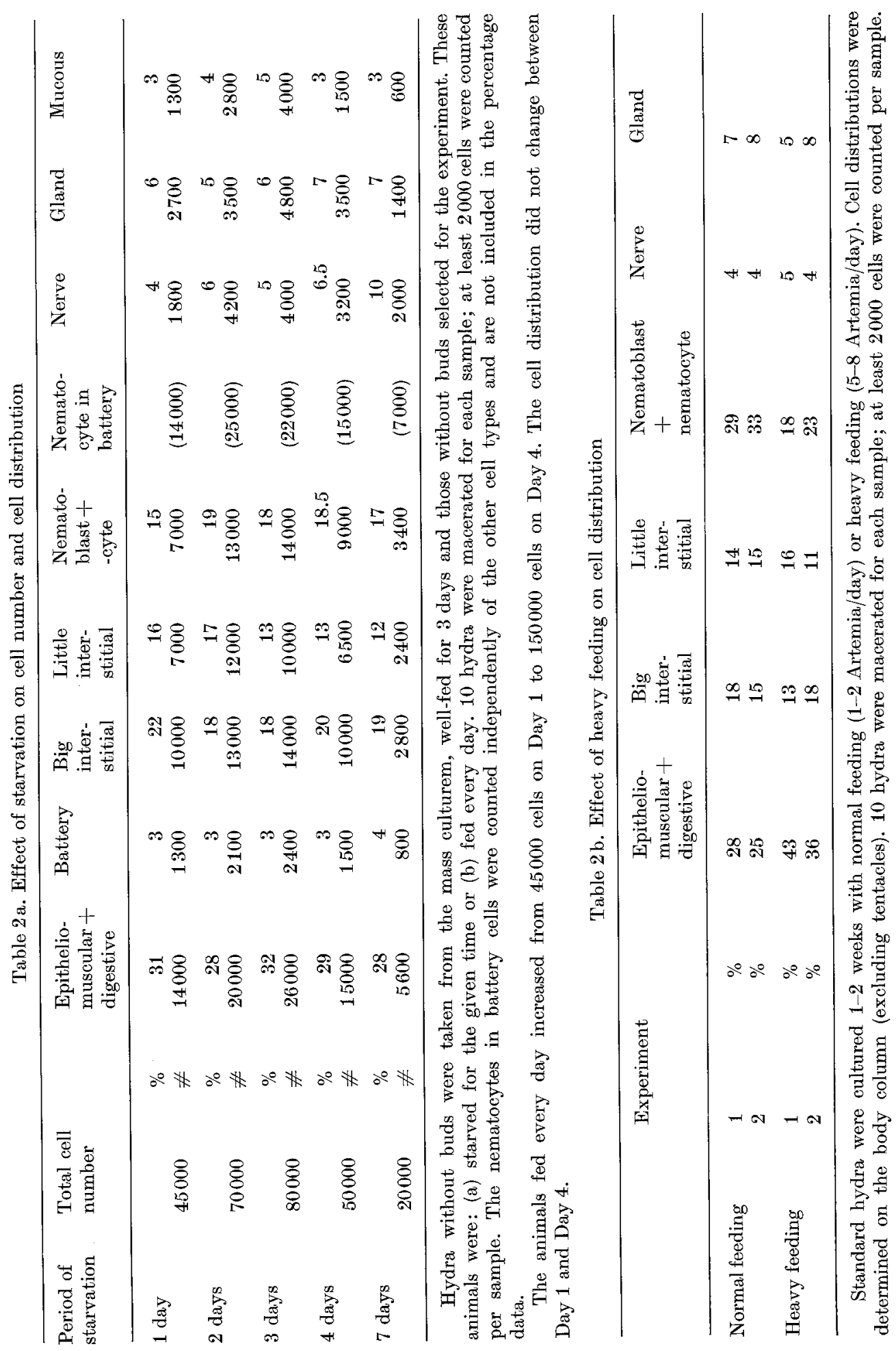


Cell Distribution in Hydra

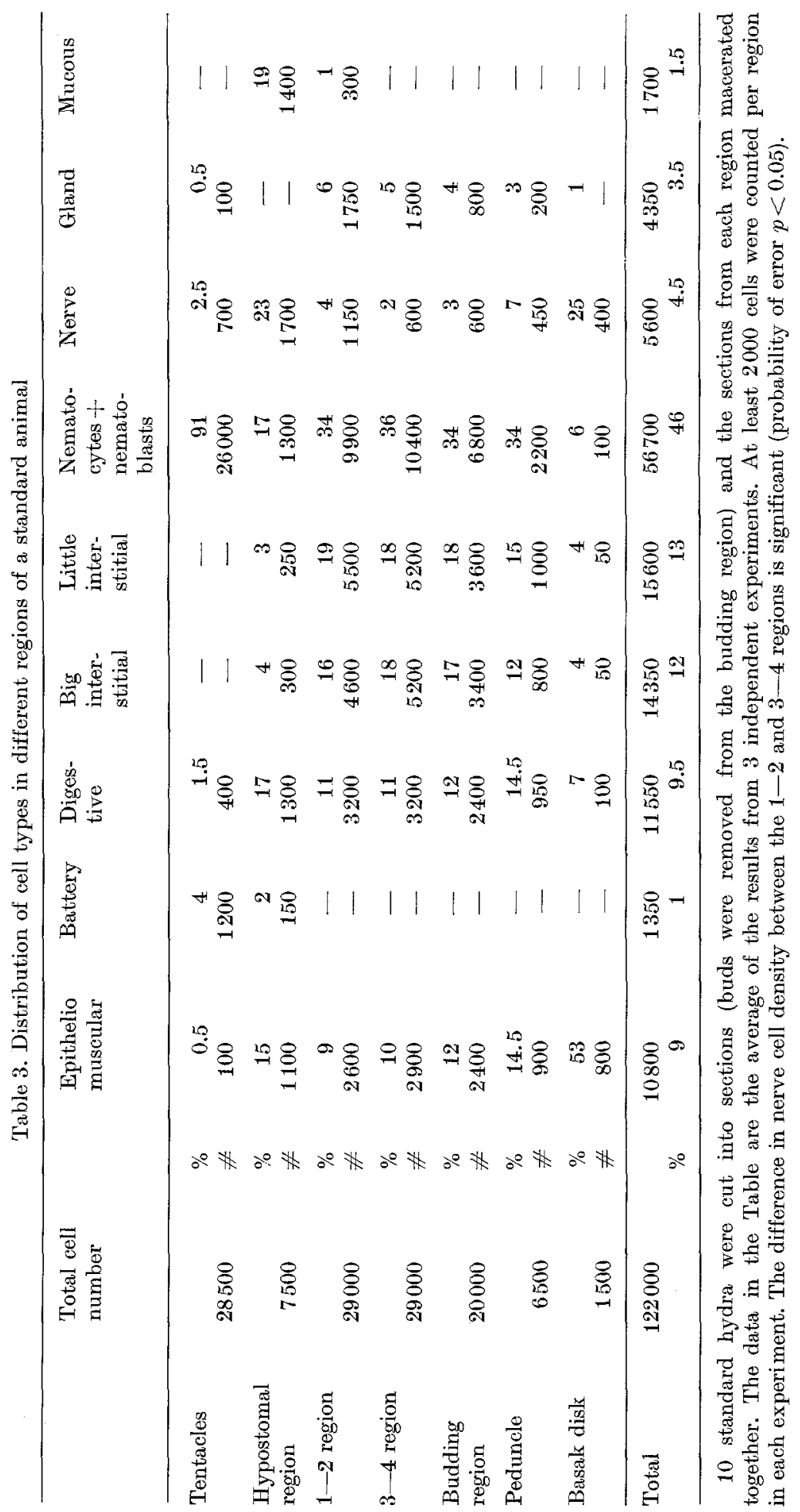



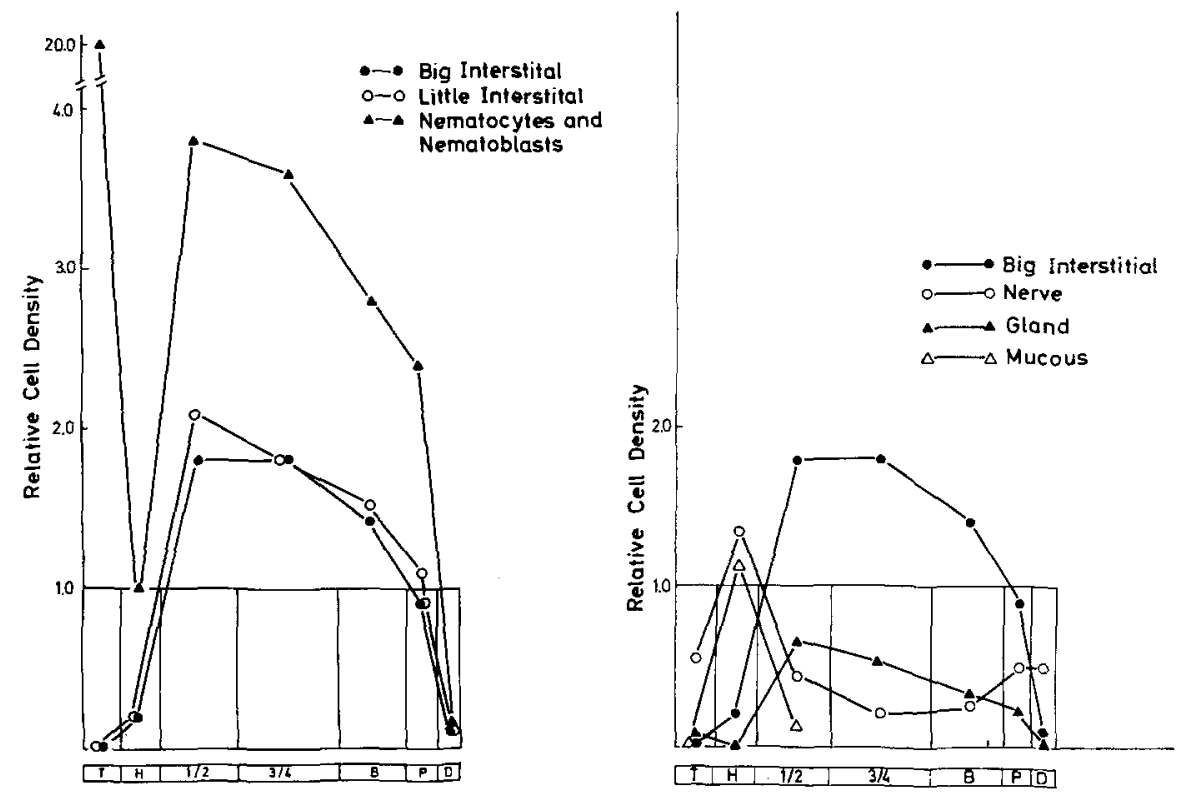

Fig. 2. Relative densities of cell types in different regions. The density of a specific cell type is defined as the ratio of the number of that cell type to the number of epithelio-muscular cells (battery cells in tentacles). The abscissa indicates the relative size of each region in terms of epithelio-muscular cells (battery cells in the tentacles). Tentacles $(T)$, hypostomal region $(H)$, upper gastric region (1/2), lower gastric region $(3 / 4)$, budding region $(B)$, peduncle $(P)$, basal disk $(D)$

animal, the ratio of the number of a particular cell type to the epithelio-muscular cells in that region is perhaps a more adequate indication of gradients of cell densities through the body regions than are percentages. These ratios are used to construct Fig. 2.

From the data contained in Table 3 and Fig. 2 the following general conclusions can be drawn:

(a) The epithelial layer of the tentacles consists of battery cells, which are modified epithelio-muscular cells. Embedded in each battery cell are about 20 nematocytes. The density of nerve cells is quite high (0.5). Compared to the 1-4 region the density of digestive cells is low.

(b) The hypostomal region is characterized by a very high density of nerve cells (30\% of all nerve cells in hydra are in the hypostome). Normalized to the epithelial cells the head contains a 4 -fold higher density than an equivalent piece of the body column. The numbers of big and little I-cells and nematoblasts are low. Mucous cells are found mainly in this region, gland cells are rare.

(c) In the other regions of the body column (regions 1-4 and the budding region) the distribution of cell types is quite uniform. The ratio of epitheliomuscular cells to digestive cells, big I-cells, little I-cells, and nematoblasts is about $1: 1: 2: 2: 4$ with a slight increase of ectodermal cells towards the budding region and a concomitant decrease in the density of the other cell types. Gland 
cells show a gradient from the 1-2 region to the budding region; the nerve cell density also decreases from the $1-2$ to the $3-4$ region $(p<0.05)$ with a slight increase in the budding region.

(d) The peduncle and, in particular, the basal disk have a higher density of nerve cells than the body column. Some of these nerve cells are different morphologically from those in the body column (David, 1972). Normalized to epithelial cells, the nerve cell density is 2 -fold higher than in the gastric region. In the basal disk, as in the hypostome, big I-cells and little I-cells, nematoblasts, and gland cells are rare.

\section{Budding}

To study the changes in cell distribution which accompany bud formation, the cell distribution in the budding region of a mature animal and in buds of various stages have been measured. The results are given in Table 4.

The earliest visible stage of budding is the appearance of a small tip in the budding region. If a disk of the budding region containing this tip is cut out, and divided into angular sections (see Table 4), the section containing the tip shows a higher percentage of nerve cells $(4 \%)$ than the section not containing the tip (1.5\% nerve cells) $(p<0.001)$, which is similar to the $3-4$ region of the animal $(2 \%)$. The total number of additional nerve cells in the tissue containing the budding tip is about 150 . Therefore, even at the earliest visible stage of budding, there are already more than 100 nerve cells which would not be there in the absence of budding.

A few hours later, when the bud is large enough to be divided into tip and base, the high density of nerve cells can be shown to occur only in the tip, not in the base of the bud. After $12-15$ hours, the bud contains about 300 nerve cells above average, and after 20 hours about 450 , still concentrated in the tip region of the bud. After 12-15 hours the first 100 mucous cells appear. They increase to to 300 at 20 hours and to 850 after 3-4 days to form the inner tissue layer of the hypostome. Only after 2-3 days does the prospective foot area of the budding animal show a significant increase in nerve cell density. The cell distribution in the new animal immediately after the dropping of the bud (3-4 days after initiation of budding) shows a distribution of cell types similar to that of mature animal, but with a somewhat higher proportion of nerve cells and a lower proportion of nematoblasts and nematocytes.

\section{Regeneration}

If the head (or foot) of a small hydra without a bud is cut off, a new head (or foot) regenerates within about two days. For head regeneration animals were cut just below the tentacle ring. At various times the prospective head region and the region directly below were removed and the cell distribution of each measured (Table 5a). 28 hours after cutting, when the first tentacle "buds" appear, there is a significant increase in nerve cells-from 3 to $6.8 \%(p<0.001)$-which further increases to $9.2 \%$ after 48 hours $\left(18^{\circ} \mathrm{C}\right)$. At $22^{\circ} \mathrm{C}$ regeneration proceeds faster; in this case the increase in nerve cell density is already observed at 24 hours. Concurrent with the nerve cell formation, there is a production of mucous cells, and a decrease in interstitial cells. Control experiments show that the region below 
H. Bode et al.:

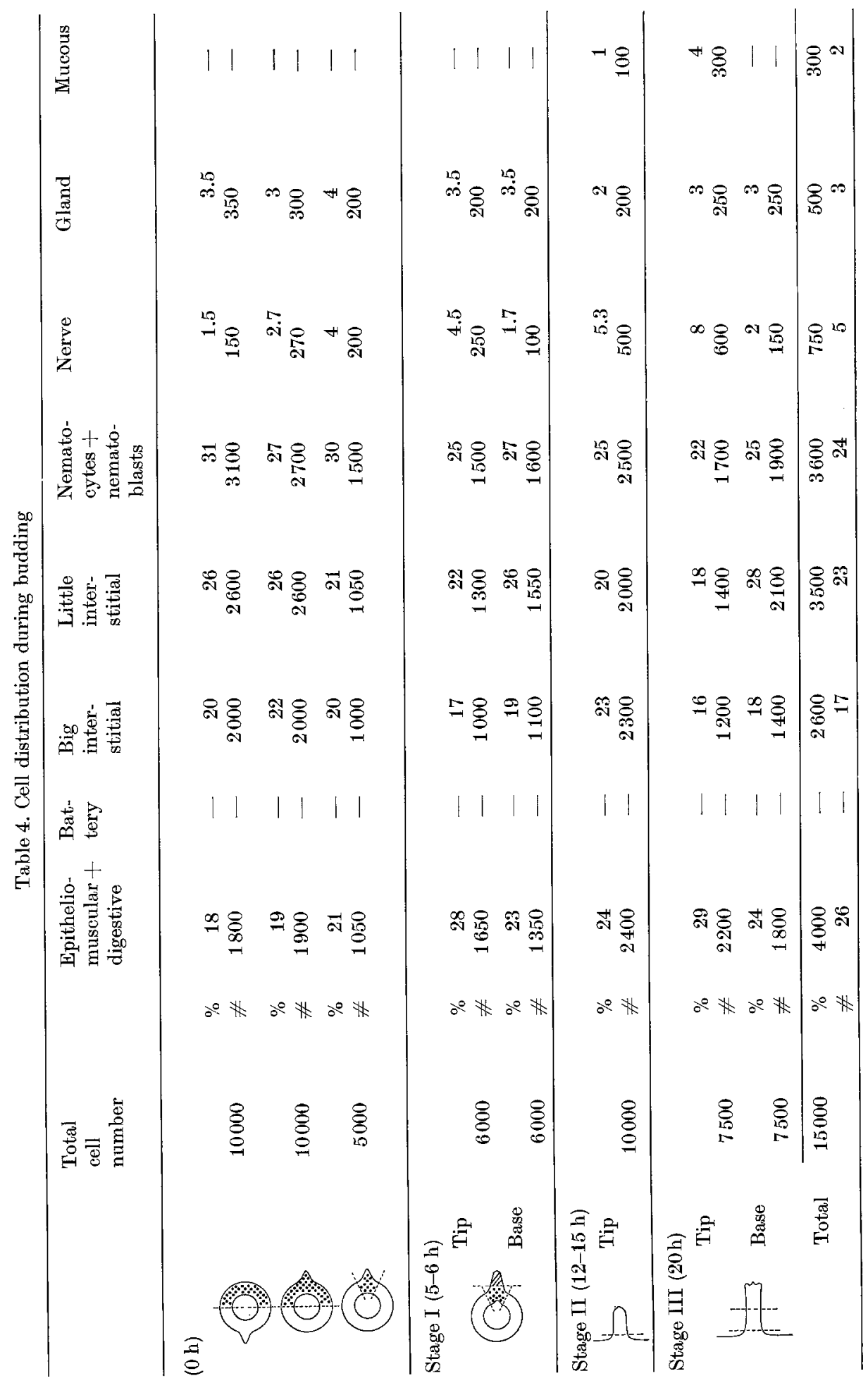




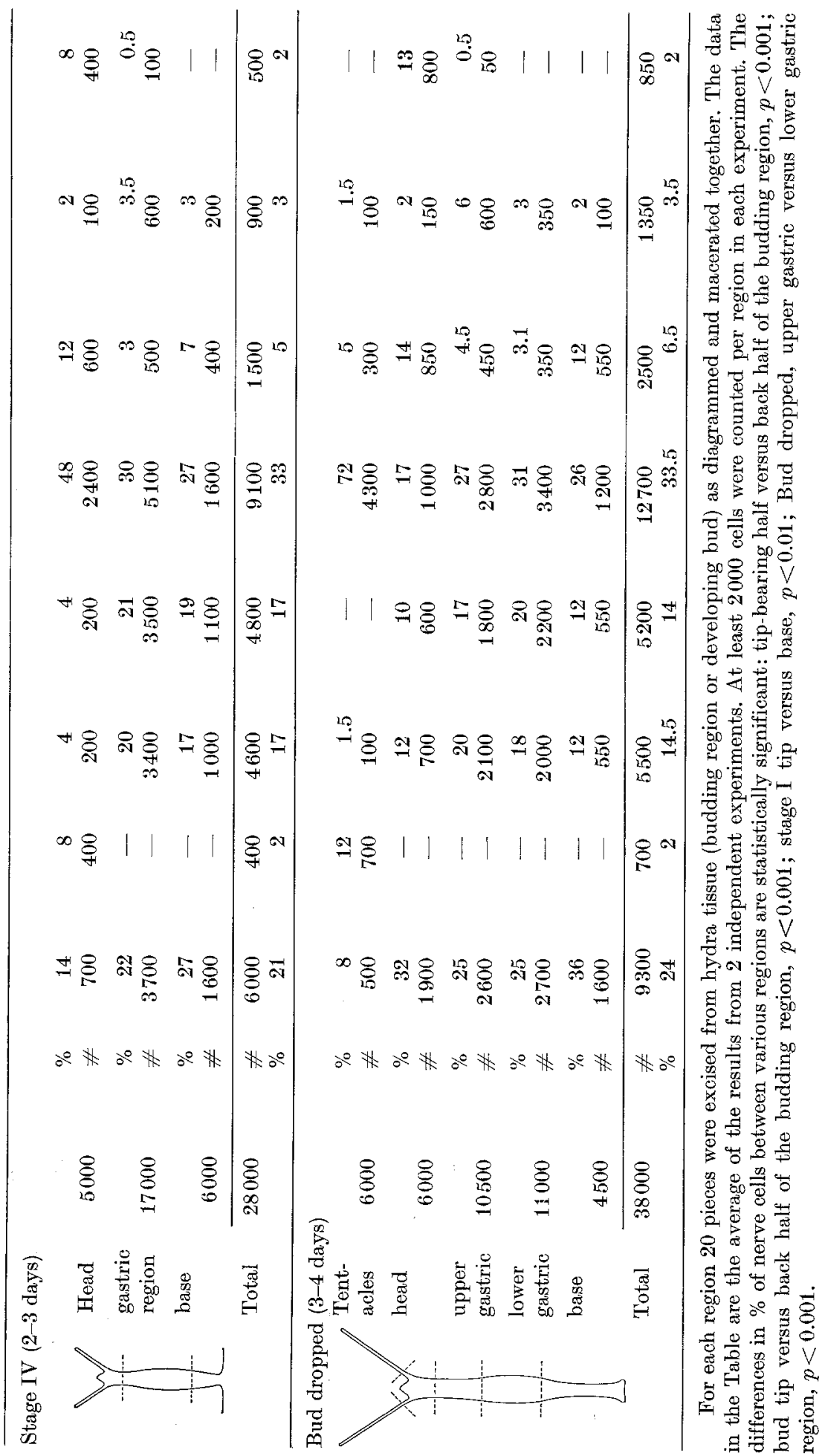


H. Bode $e t a l$ :

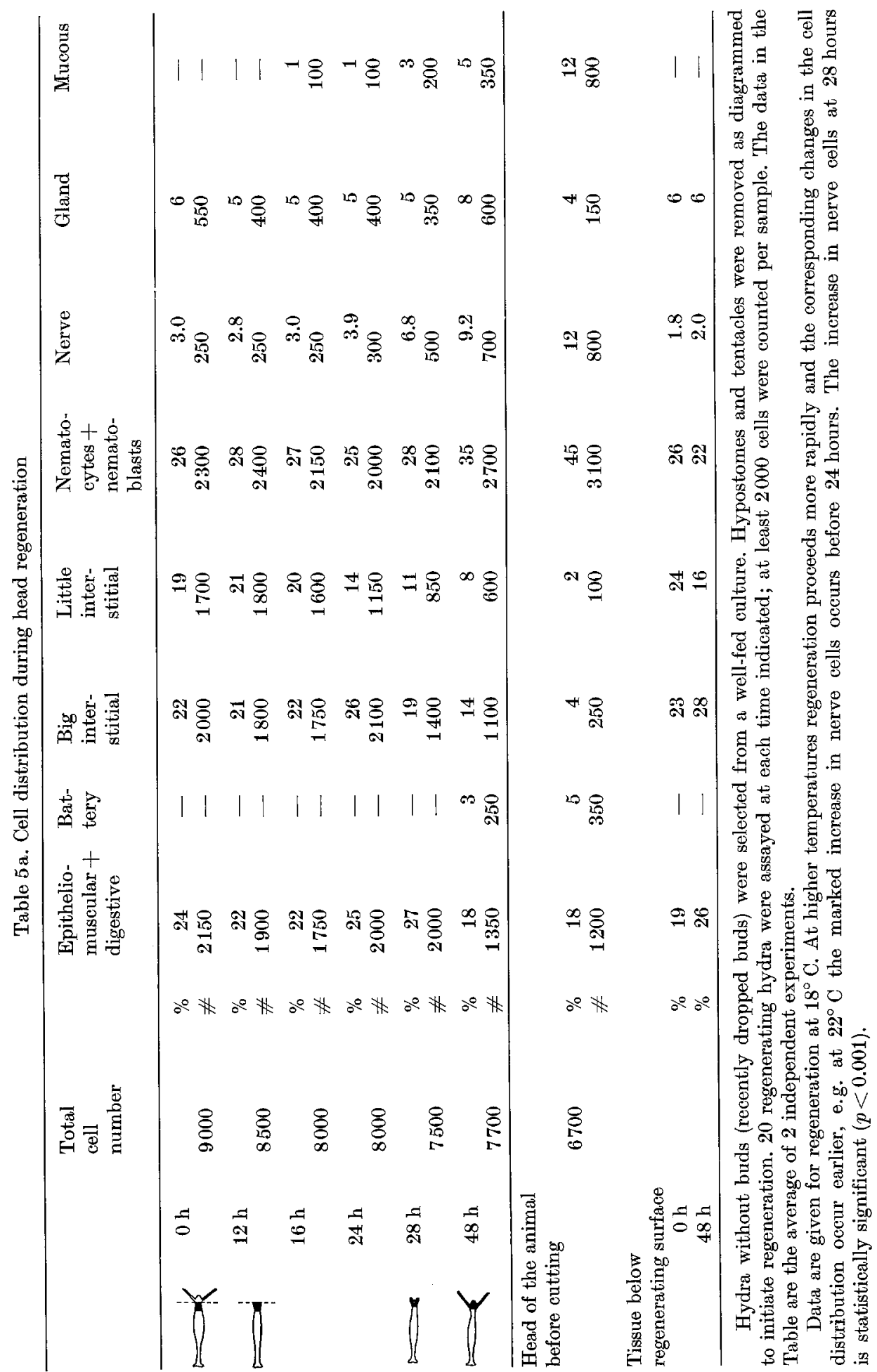




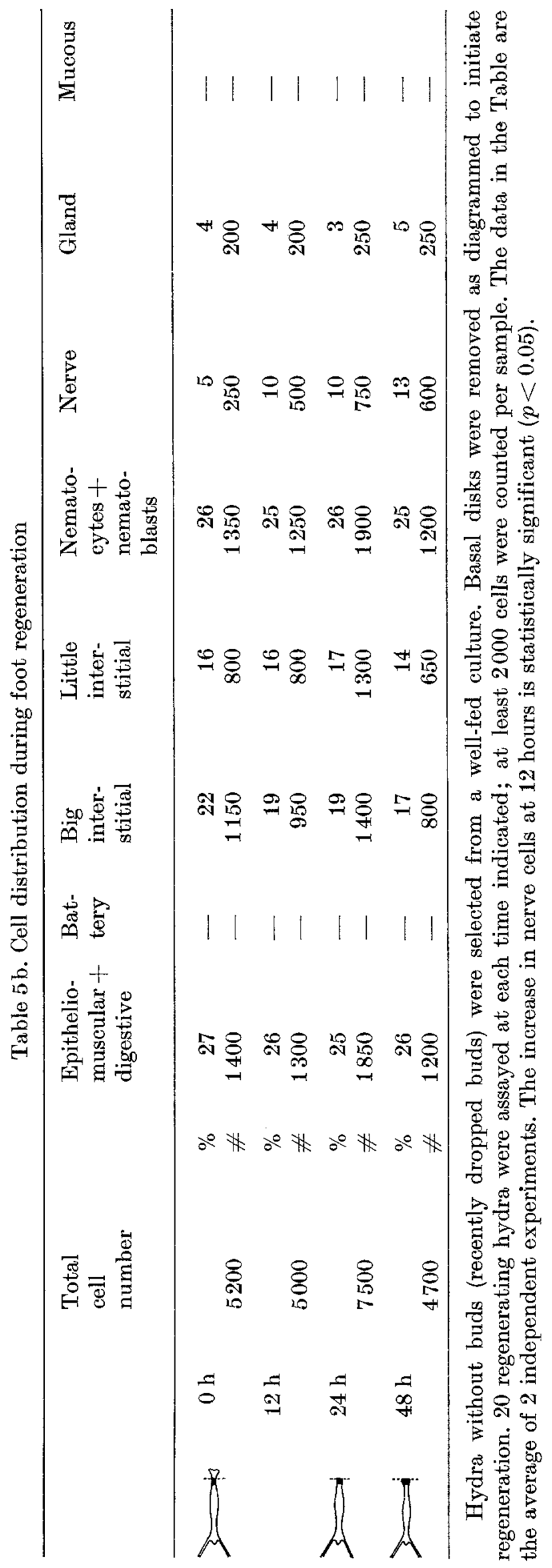


the regenerating head does not change its cell distribution significantly during the same period of time. There is no change in nerve cell density, though some decrease in little I-cells and nematoblasts.

Budding animals have a slow rate of head regeneration. The first doubling in nerve cell density is nevertheless observed after 24 hours. However, the mucous cells appear only after $\mathbf{4 8}$ hours, when the first tentacle buds become visible.

For foot regeneration a cut was made through the peduncle region just above the basal disk. Regenerating sections showed an increase in nerve cell density $(p<0.05)$ already 12 hours after cutting (Table $5 \mathrm{~b})$.

\section{Discussion}

\section{(a) Cell Numbers and Distribution}

It has been shown that the number of cells per animal and, to a minor extent, the cellular composition depend on the state of growth - the stage between newly dropped bud and mature animal-, on feeding and on temperature. A well-fed "mature" animal, grown at $20^{\circ} \mathrm{C}$ has about 120000 cells. A newly dropped bud from the same animal contains approximately 40000 cells. The 120000 cells are composed of 24000 ectoderm, endoderm and battery cells, 57000 nematoblasts and nematocytes, about 15000 big and 15000 little I-cells, 6000 nerve cells, 4000 gland cells, and 2000 mucous cells. Lowering the temperature from $20^{\circ} \mathrm{C}$ to $16^{\circ} \mathrm{C}$ leads to an 1.5- to 2-fold increase in the number of cells per animal (parent and bud), starvation to an eventual decrease. Whereas the influence on the total cell number is marked, the cell composition is less affected.

Nerve Cells

The head (including hypostomal region and tentacles) of a standard animal contains more than $40 \%$ of all the nerve cells. Another $40 \%$ form a gradient decreasing from the 1 to the 4 region of the body column, followed by a slight increase in density in the budding region. The peduncle and basal disk are again rich in nerve cells.

In the course of budding and during head and foot regeneration a region of low nerve cell density acquires the high nerve cell density characteristic of the region being formed. We have shown that in all three cases the increase in nerve cell density is the first change detected in cell distribution.

In the process of budding, the first 100 nerve cells (above the average value of the surrounding tissue) are already present, when the bud tip just becomes detectable, with more nerve cells appearing in the bud within the next two days. Head regeneration is also accompanied by an early increase in nerve cell density which doubles about 1 day after cutting, with a further increase for 1-2 days. Since nerve cells can only appear some time after the determination of precursor cells, determination must occur very early in regeneration as well as budding. In foot regeneration the increase in nerve cell density is already observed 12 hours after cutting, and does not increase significantly thereafter. The earlier appearance of nerve cells in foot as compared to head regeneration implies that determination is rapid or that the process of differentiation from precursor cell to nerve cell is shorter in the foot or that predetermined and partially differentiated cells are triggered to complete differentiation. 


\section{Interstitial Cells}

Interstitial cells are widely considered as multipotent cells. Probably, part of the I-cells counted represent uncommitted multipotent cells, another part may be determined to become nerves and nematocytes.

In agreement with most studies on histological sections, we find that interstitial cells do not accumulate significantly during budding or regeneration. These processes make use of the preexisting interstitial, epithelial and digestive cells of the gastric region. On the other hand, I-cell concentration is low in the head and foot region, where nerve cell density is high. Possibly, determination of nerve cells occurs at the expense of determination of nematoblasts, and might, in addition, lead to a local depletion of the truly multipotent fraction of interstitial cells.

\section{Nematocytes and Nematoblasts}

Most nematocytes are found in the tentacles, whereas almost all nematoblasts occur in the gastric region. In the course of maturation they migrate to the battery cells of the tentacles. The total number of nematocytes is similar to that of nematoblasts under the conditions of growth studied, suggesting that the turnover time of nematocytes is of the same order of magnitude as that of nematoblasts. Nematoblasts are fairly evenly distributed along the body column, whereas their concentration in the head region through which they must pass is low. This indicates that nematoblasts may migrate only during a small fraction of their maturation time, close to or upon maturation.

\section{Gland Cells, Mucous Cells}

Gland cells show a gradient in the gastric region, and are nearly absent in the hypostome and foot region. Mucous cells are present primarily in the hypostomal region. During head regeneration, the first mucous cells appear when tentacle buds become visible and thereafter increase continuously for several days. Thus, in contrast to nerve cells which appear very early in the development of a bud or during regeneration, the mucous cells appear only when the final morphological structure, the hypostome, is being formed. Since mucous cells are not present in the regenerating piece at 0 hours, they must arise from other cells. Later during regeneration the density of gland cells first increases and then decreases as soon as mucous cells appear. This may be taken to indicate that gland cells, or cells with the morphological appearance of gland cells, are the precursors or intermediates in the development of mucous cells. However, as earlier work (reviewed by Kanaev, 1952) has suggested, another possibility is that they arise from the I-cells (basal cells) of the endoderm.

\section{(b) Polarity, Morphogenetic Gradients, Differentiation}

Any concept of regeneration in hydra has to deal with polarity effects. Pieces of body column usually regenerate the head distally and the foot proximally. Polarity could be due to a polar array of polarized cells. Another possibility would be a gradient of substances within one cell type, e.g. epithelial cells. In these cases, polarity would not necessarily be reflected in the distribution of cell types. 
On the other hand, polarity could be due to a graded distribution of one or several cell types. Obviously, only cell types showing a graded distribution along: the body column could be responsible for polarity in this case.

Possibly, the gland cells, or some as yet unidentified subgroup of the interstitial cells, could define polarity. In view of the data, however, a more suggestive hypothesis would be to attribute polarity partly or mainly to nerve cells. Their density is highest in the head region, and a gradient in nerve cell density extends down the body column in both mature hydra (Table 3) and dropped buds (Table 4). Nerve cells have been implicated as sources of morphogenetically active substances by Lentz (1966) and by Burnett (1966).

The slight increase in nerve cells in the budding region may be due to newlyforming buds, since it is not typical for non-budding tissue in this region. This hypothesis, however, requires the assumption that foot nerve cells do not contribute to the primary morphogenetic gradient which defines polarity. Increased nerve density in peduncle and basal disk may indicate a secondary center of tissue organization as is also suggested by the tissue transplantation experiments of MacWilliams et al. (1970).

Determination of nerve cells occurs early in the course of regeneration and budding. This shows that the morphogenetic gradient causing nerve cell determination cannot itself be the product of long processes of differentiation, but is probably triggered and established in preexisting cells. The observation that nerve cell densities continue to increase over longer periods of time indicates that nerve cell determination is not confined to a single event. The data presented here indicate that some cell determination, such as nerve cell determination, probably occurs too early to be dependent on morphogenetic events. On the other hand, to what extent morphogenesis depends on nerve cell formation remains to be decided.

Acknowledgement. We thank G. Hansmann, K. Flick, and D. Challoner for helpful contributions to this research. C. N. David is the recipient of a postdoctoral fellowship from Helen Hay Whitney Foundation.

\section{References}

Burnett, A. L.: The acquisition, maintenance and lability of the differentiated state in hydra. In: The stability of the differentiated state (H. Ursprung and W. Beermann, ed.). BerlinHeidelberg-New York: Springer 1966.

Campbell, R. D.: Tissue dynamies of steady state growth in Hydra littoralis. Develop. Biol. $15,487-502(1967)$.

David, C. N.: Quantitative method for maceration of hydra tissue. Wilhelm Roux' Archiv, 171, 259 (1972).

Kanaev, J. J.: Hydra. Essays on the biology of fresh water polyps, originally published by Soviet Academy of Sciences, Moscow; ed. by H. M. Lenhoff (1952).

Lentz, T. L.: The cell biology of hydra. Amsterdam: North-Holland Publ. Co. 1966.

Loomis, W. F., Lenhoff, H. M.: Growth and sexual differentiation of hydra in mass eulture. J. exp. Zool. 132, 555-573 (1956).

MacWilliams, H. K., Kafatos, F. C., Bossert, W. H.: The feedback inhibition of basal disk regeneration in Hydra has a continuously variable intensity. Develop. Biol. 23, 380-398 (1970).

Tardent, P.: Axiale Verteilungsgradienten der interstitiellen Zellen bei Hydra und Tubularia und ihre Bedeutung für die Regeneration. Wilhelm Roux' Arch. Entwickl.-Mech. Org. 146, 593-649 (1954). 
Tardent, P.: Regeneration in hydrozoa. Biol. Rev. 38, 293-333 (1963).

Webster, G.: Morphogenesis and pattern formation in hydroids. Biol. Rev. 46, 1-46 (1971). Wolpert, L., Hicklin, J., Hornbruch, A.: Positional information and pattern regulation in regeneration of hydra. In: Control mechanisms of growth and differentiation. Symp. Soc. Exp. Biol. XXV. Cambridge: Cambridge University Press 1971.

Professor Dr. A. Gierer

Max-Planck-Institut für Virusforschung Abteilung Molekularbiologie

D-7400 Tübingen

Spemannstraße 35

Federal Republic of Germany 